\title{
Analysis of Mendelian inheritance and genetic linkage in microsatellite loci of Eucalyptus urophylla S.T. Blake
}

\author{
S. Pupin 1 , L.N. Rosse ${ }^{2}$, I.C.G. Souza ${ }^{3}$, J. Cambuim ${ }^{1}$, C.L. Marino ${ }^{4}$, \\ M.L.T. Moraes ${ }^{1}$ and A.M. Sebbenn ${ }^{5}$ \\ ${ }^{1}$ Departamento de Fitotecnia, Tecnologia de Alimentos e Sócio Economia, \\ Faculdade de Engenharia, Universidade Estadual Paulista, Ilha Solteira, SP, Brasil \\ ${ }^{2}$ Eldorado Brasil, Três Lagoas, MS, Brasil \\ ${ }^{3}$ Suzano Papel e Celulose, Itapetininga, SP, Brasil \\ ${ }^{4}$ Departamento de Genética, Instituto de Biociências, \\ Universidade Estadual Paulista, Botucatu, SP, Brasil \\ ${ }^{5}$ Instituto Florestal de São Paulo, São Paulo, SP, Brasil \\ Corresponding author: S. Pupin \\ E-mail: silvelise.pupin@gmail.com \\ Genet. Mol. Res. 16 (3): gmr16039713 \\ Received May 4, 2017 \\ Accepted July 21, 2017 \\ Published August 17, 2017 \\ DOI http://dx.doi.org/10.4238/gmr16039713
}

Copyright $(2017$ The Authors. This is an open-access article distributed under the terms of the Creative Commons Attribution ShareAlike (CC BY-SA) 4.0 License.

\begin{abstract}
Eucalyptus urophylla is an important species in the Brazilian forest sector due to its rapid growth rates and resistance to disease. The aim of this study was to verify Mendelian inheritance, genetic linkage, and genotypic disequilibrium for 15 microsatellite loci, with the goal of producing a robust set of genetic markers. Mendelian inheritance and genetic linkage analyses were carried out using genotypes from maternal trees, and their open-pollinated seeds and genotypic disequilibrium were assessed using adult trees. By comparing heterozygous maternal genotypes and their seeds, we found no significant deviations from the expected 1:1 Mendelian segregation and the expected 1:1:1:1 segregation hypothesis for pairwise loci. For adult trees, we did not find strong evidence of genotypic imbalance for pairwise loci. Our results indicated that the analyzed set of
\end{abstract}


microsatellite loci could be used to carry out analyses of genetic diversity, mating system, and parentage in E. urophylla.

Key words: Eucalypt; Genetic markers; Population genetics; Seed orchards; Tree breeding

\section{INTRODUCTION}

The impact of classic quantitative genetics on Brazil's high productivity levels in Eucalyptus planted forests is indisputable. However, in the last 25 years, possibilities for further progress have arisen due to technological advancements in molecular markers, sequencing methods, and genetic engineering (Harfouche et al., 2014; Barabaschi et al., 2016). Single sequence repeats (SSR) have been used since 1996 as an auxiliary tool to inform genetic improvement and conservation plans (Byrne et al., 1996), providing essential information on levels of genetic diversity within and among populations, inbreeding, effective population size, breeding system, and gene flow. Among the species cultivated in tropical climate regions, Eucalyptus urophylla is planted commercially as a pure species or as a hybrid, mainly with E. grandis (Hodge and Dvorak, 2015). The wood can be used in civil construction and pulp and cellulose production (Carvalho et al., 1998). The species is also resistant to diseases such as eucalyptus rust (Puccinia psidii), wilt (Ceratocystis fimbriata), and cancers (Chrysoporthe cubensis and Coniothyrium zuluense) (Carvalho et al., 1998).

SSR markers have been used extensively due to their codominant inheritance and high locus polymorphism (Grattapaglia et al., 2012; Randall et al., 2015). However, it is critical to confirm if SSR loci employed in population genetic analyses are in fact genetic markers. These markers cannot suffer from segregation distortions and genetic association between loci, as this would negate the principle of random association between alleles of different loci and generate redundant information. Thus, we assess the Mendelian inheritance, genetic linkage, and genotypic disequilibrium for 15 SSR loci of E. urophylla to develop a robust set of genetic markers for genetic diversity, inbreeding, and parentage analyses.

\section{MATERIAL AND METHODS}

Two seed orchards of E. urophylla (SO1, SO2) and a progeny test (PT) were used for the analyses. The study populations are installed in the Teaching, Research and Outreach Farm (FEPE), Ilha Solteira Faculty of Engineering (FEIS/UNESP), in the municipality of Selvíria, Mato Grosso do Sul State, Brazil. For DNA analysis, we sampled leaves from 79 and 298 adult trees in SO1 and SO2, respectively. In PT, we sampled 605 seedlings (denominated seeds) from 23 mother trees. The extraction and purification of the DNA were performed based on the CTAB method (Doyle and Doyle, 1987) and amplification was performed using PCR (polymerase chain reaction), with minor modifications to the protocol (see Faria et al., 2011). For the genotyping of individuals, we used EMBRA microsatellite markers (Brondani et al., 1998, 2006): 15 SSR loci for SO2 and PT; and 13 common SSR loci for SO1. The genetic characterization was performed in multiplex systems, with multi-fluorescence detection, in an ABI 3100XL automatic capillary sequencer. Raw genotypic data (electropherograms) were exported from the sequencer using the Genotyper software (Applied Biosystems) and adjusted to unity using the TANDEM software (Matschiner and Salzburger, 2009). Molecular analyses were performed at the Hereditas/Genomax Laboratory in Brasília, Brazil.

Genetics and Molecular Research 16 (3): gmr16039713 
To investigate the Mendelian inheritance of the SSR loci, we compared maternal heterozygous mother tree genotypes with their seeds, using the method described by Gillet and Hattemer (1989). The assumptions of the method are that the loci have regular segregation and their alleles follow Mendelian inheritance patterns, which are based on the following conditions: i) regular meiotic segregation during ovule production; ii) random fertilization of ovules by each type of pollen; iii) absence of differential selective viability in the progenies prior to the investigation by genetic markers; iv) a co-dominant relationship between alleles. The method further requires that all progeny of a tree possess a maternal allele. In cases of a heterozygous mother tree (e.g., $A_{i} A_{j}, i \neq j$ ), the following are required: a) each one within progeny must have one allele of the maternal tree, $A_{i}$ or $A_{j}$; b) the number of heterozygous progeny $A_{i} A_{j}\left(n_{i j}\right)$ must be equal to the sum of the number of homozygous progeny $A_{i} A_{i}\left(n_{i i}\right)$ and $A_{j} A_{j}\left(n_{i j}\right): n_{i j}=n_{i i}+n_{i j}$; and c) the number of heterozygous progeny $A_{t} A_{k}\left(n_{i k}\right)$ must be equal to the number of heterozygous progeny $A_{f} A_{k}\left(n_{j k}\right)$, or $n_{i k}=n_{j k}$, in other words, $k \neq i, j$. The observed segregation of each progeny from a heterozygous maternal tree for a given locus was statistically compared to that expected for the segregation hypothesis of 1:1, using the $G$-test (Sokal and Rohlf, 1981):

$$
G=2\left[n_{i j} \ln \left(\frac{n_{i j}}{E(n 1)}\right)+\left(n_{i i}+n_{i j}\right) \ln \left(\frac{\left(n_{i i}+n_{j j}\right)}{E(n 1)}\right)\right]
$$

where $\ln$ is the natural logarithm, $E(n 1)$ is the expected number of offspring genotypes $A_{i} A_{j}$ $\left(n_{i j}\right)$ and $A_{i} A_{i}+A_{j} A_{j}\left(n_{i i}+n_{j j}\right): E(n 1)=0.5\left(n_{i j}+n_{i i}+n_{i j}\right)$, or:

$$
G=2\left[n_{i k} \ln \left(\frac{n_{i k}}{E(n 2)}\right)+n_{j k} \ln \left(\frac{n_{j k}}{E(n 2)}\right)\right]
$$

where $E(n 2)$ is the expected number of genotypes for alleles $A_{i} A_{k}\left(n_{i k}\right)$ and $A_{f} A_{k}\left(n_{j k}\right): E(n 2)=0.5\left(n_{i k}+\right.$ $n_{j k}$. To avoid false positives, the $G$-test was determined only when $n 1$ and $n 2$ were $\geq 15$. Deviation from the $G$-test between the observed and expected segregation was determined as statistically significant using the Bonferroni correction for multiple comparisons $(95 \%, \alpha=0.05)$.

To determine if the loci were genetically linked, we tested pairs of loci using genetic information from mother trees that were doubly heterozygous for two loci $\left(A_{i} A_{i}, B_{i} B_{m}\right)$. The segregation was recorded in their progeny. In this case, the null hypothesis $\left(H_{\mathrm{O}}\right)$ was a normal Mendelian segregation of 1:1:1:1. The normal segregation hypothesis between pairs of loci was accepted or rejected based on a maximum likelihood $G$-test (Sokal and Rohlf, 1981) performed for each progeny:

$$
G=2\left[n_{i l} \ln \left(\frac{n_{i l}}{E(n)}\right)+n_{i m} \ln \left(\frac{n_{i m}}{E(n)}\right)+n_{j l} \ln \left(\frac{n_{j l}}{E(n)}\right)+n_{j m} \ln \left(\frac{n_{j m}}{E(n)}\right)\right] \text { (Equation 3) }
$$

where $n_{i l}, n_{i m}, n_{j l}$, and $n_{j m}$ are the observed numbers of phenotypes $A_{i} B_{l}, A_{i} B_{m}, A_{j} B_{l}$, and $A_{j} B_{m}$, respectively, and $E(n)$ is the expected number of each genotype $A_{i} B_{l}, A_{i} B_{m}, A_{j} B_{l}$, and $A_{j} B_{m}{ }^{m}$, calculated by $E(n)=0.25\left(n_{i l}+n_{i m}+n_{j l}+n_{j m}\right)$. Again, we applied the Bonferroni correction for multiple comparisons $(95 \%, \alpha=0.05)$ to avoid false positives.

The genotypic disequilibrium test between pairwise loci was only performed for adult samples. Estimates of gene frequencies based on open-pollinated progeny arrays are biased because each progeny has at least one maternal allele, resulting in genotypic disequilibrium. This

Genetics and Molecular Research 16 (3): gmr16039713 
analysis was carried out using the FSTAT 2.9.3.2 software (Goudet, 2002). The probabilities of the significance test were obtained by permutation of alleles among individuals, associated with a Bonferroni correction for multiple comparisons $(95 \%, \alpha=0.05)$.

\section{RESULTS}

No deviation from 1:1 Mendelian segregation was detected for 13 of the 15 microsatellite loci $(86.6 \%)$ analyzed for progenies of heterozygous maternal trees (Table 1). Significant deviations were identified in two cases: EMBRA2 (18.29) for tree 95 and EMBRA63 (12.67) for trees 10 and 155. Of the $733 G$-tests carried out for pairwise loci, only $26(3.5 \%)$ were significantly different than expected under the hypothesis of 1:1:1:1 independent Mendelian segregation (Table 2). As

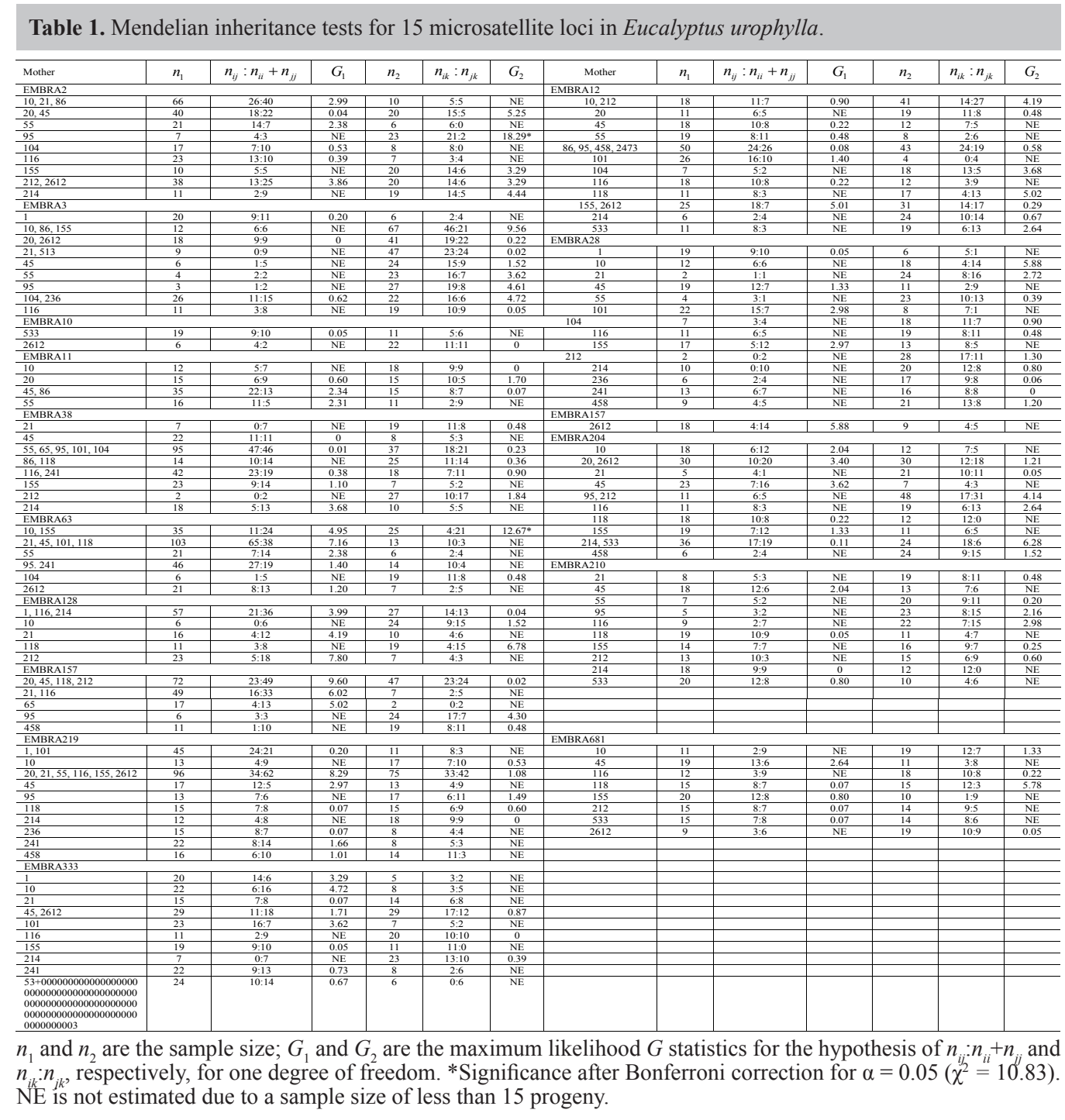

Genetics and Molecular Research 16 (3): gmr16039713 


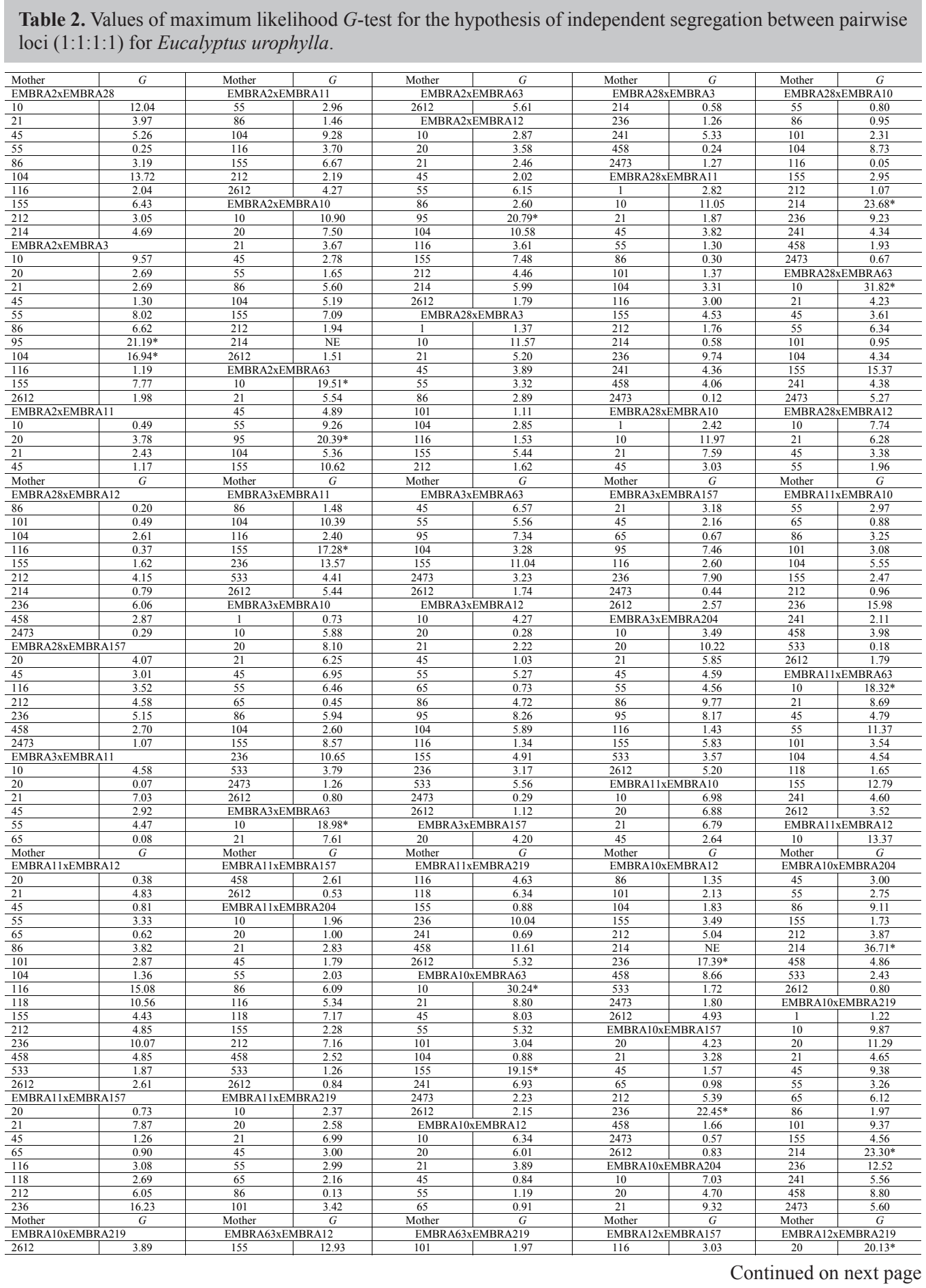

Genetics and Molecular Research 16 (3): gmr16039713 


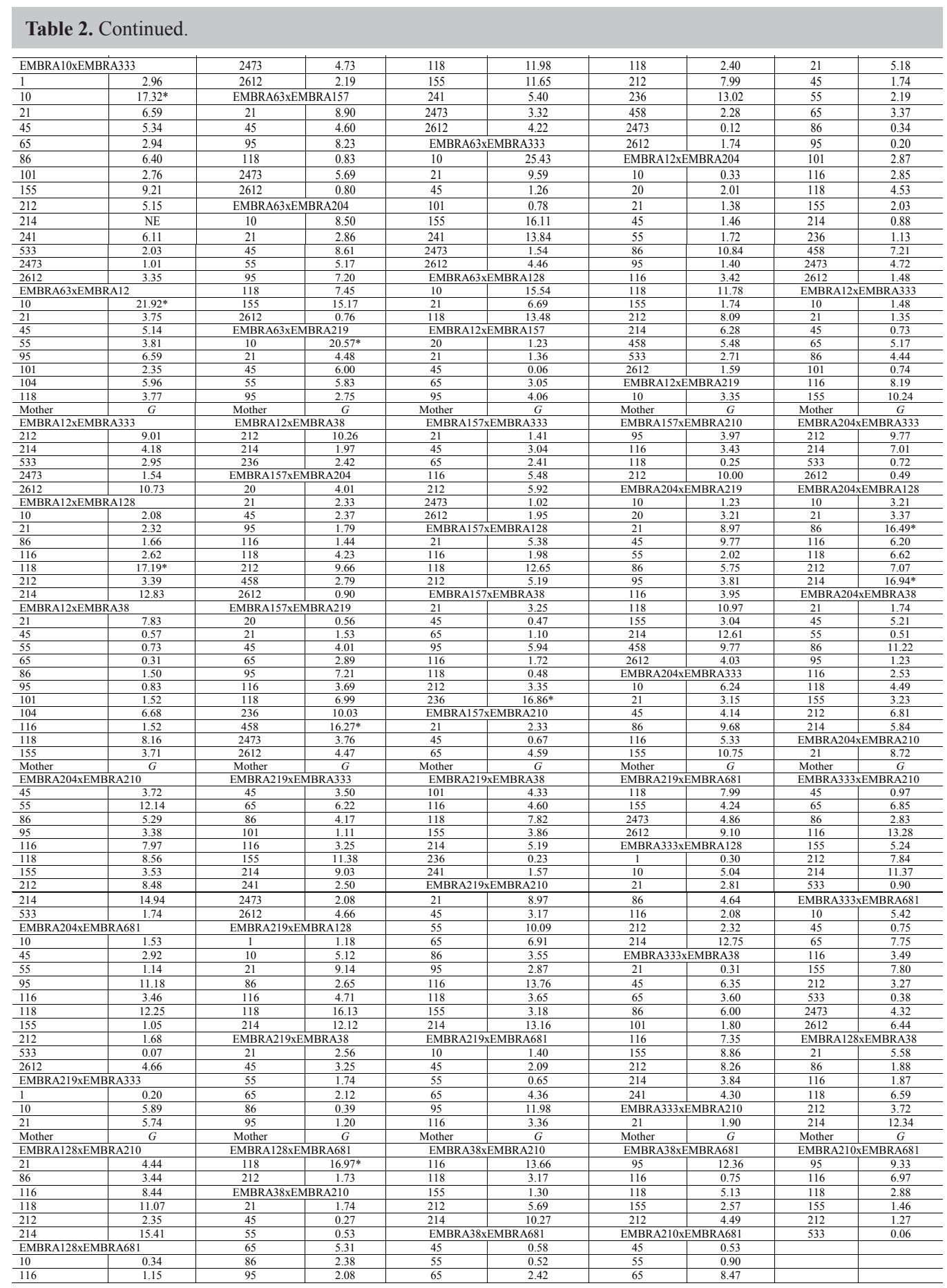

*Significance after Bonferroni correction for $\alpha=0.05\left(\chi^{2}=16.27\right) . G$ is the $G$-test at three degrees of freedom.

Genetics and Molecular Research 16 (3): gmr16039713 
the deviations were observed in different families, our results do not provide solid evidence of genetic linkage between the loci (Table 3). Considering the two seed orchards, only $5.8 \%$ of the pairwise loci were significant for genotypic disequilibrium. In both orchards, significance was found between the following loci: EMBRA681 x EMBRA2 and EMBRA204 x EMBRA210.

\begin{tabular}{l} 
Table 3. Genotypic disequilibrium between pairwise microsatellite loci for Eucalyptus urophylla adult trees \\
from seed orchard SO1 (lower diagonal) and SO2 (upper diagonal). \\
\begin{tabular}{l|c|c|c|c|c|c|c|c|c|c|c|c}
\hline \\
\hline
\end{tabular} \\
\hline
\end{tabular}

P values represent the probability of genotypic disequilibrium after 1440 permutations of alleles among individuals. Value at which results are deemed significant after Bonferroni correction: $* \mathrm{P}=0.00021(\alpha=0.05)$.

\section{DISCUSSION}

Mendelian 1:1 segregation at the individual locus was confirmed for 13 of the tested SSR loci. Significant deviations were only found in isolated cases of EMBRA2 (tree 95) and EMBRA63 (trees 10 and 155), where we found disproportionate results for segregated maternal alleles in their progenies. Of the 30 seeds collected from mother tree $95(110 / 132)$, 27 received allele $110(90 \%)$; for trees 10 and $155(168 / 172), 30(100 \%)$, and $26(86.7 \%)$ of the 30 offspring, respectively, received allele 172. These results suggest the occurrence of segregation deviation caused by pre- or post-zygotic factors. Segregation deviations in a limited number of SSR loci of some families can also be caused by sampling errors, small family size, misinterpretation of allele size, or the presence of null alleles (Danner et al., 2013; Tambarussi et al., 2013). Nevertheless, these limited instances found herein do not indicate that the loci deviate from the expected Mendelian inheritance and we can conclude that the 15 EMBRA SSR markers are genetic markers.

The small numbers of significant $G$-test deviations from independent segregation between pairs of loci $(1: 1: 1: 1)$ indicate that the loci segregate independently. Significant values were observed for different families and occurred more frequently between the following pairs: EMBRA2xEMBRA3, EMBRA2xEMBRA63, and EMBRA204xEMBRA128. The significant linkage may be the result of true genetic linkage or deviations from 1:1 Mendelian segregation (Manoel et al., 2015; Moraes et al., 2015), as observed for EMBRA2 and EMBRA63. The absence of linkage between the loci is important concerning models used in population genetic analyses, which assume random segregation between alleles of different loci.

Considering the two seed orchards, our results do not indicate genotypic disequilibrium. Only $5.8 \%$ of the results between pairs of loci were significant, and the majority (78\%) was detected in SO2. This is likely due to relatedness that exists between the 79 and 298 adult trees on SO1 and SO2, respectively, and the unbalanced proportion of individuals within families that remained after selective thinning during orchard establishment. In both orchards, significance was found between loci EMBRA681xEMBRA2 and EMBRA204xEMBRA210. The imbalance may be affected by selection, recombination, migration, population reduction, 
genetic drift, and population structure (Kumar et al., 2004). Tarazi et al. (2010) found genotypic disequilibrium between pairwise loci in open-pollinated seeds of Copaifera langsdorffi, probably due to the inheritance of maternal alleles. When the family structure was considered in the analysis, with a limited number of seeds per family, a few significant values of genotypic disequilibrium were detected, thus supporting the idea that the inheritance of maternal alleles produces genotypic disequilibrium. In conclusion, our results show that the 15 SSR loci analyzed herein form a robust set of genetic markers, which can be used to assess issues related to genetic diversity, mating system, and parentage analysis, providing more in-depth information that can be used to advance E. urophylla breeding programs.

\section{ACKNOWLEDGMENTS}

Research supported by Fundação de Amparo à Pesquisa do Estado de São Paulo (FAPESP; Project \#2014/03407-7), Eldorado Brasil, Suzano Papel e Celulose, and Conselho Nacional de Desenvolvimento Científico e Tecnológico (CNPq). The authors would like to thank CNPq for research funding provided to A.M. Sebbenn and M.L.T. Moraes. We also extend our special thanks to Universidade Estadual Paulista/UNESP and to Dr. Evelyn Nimmo for her correction of the English in the manuscript.

\section{REFERENCES}

Barabaschi D, Tondelli A, Desiderio F, Volante A, et al. (2016). Next generation breeding. Plant Sci. 242: 3-13. https://doi. org/10.1016/j.plantsci.2015.07.010

Brondani RPV, Brondani C, Tarchini R and Grattapaglia D (1998). Development, characterization and mapping of microsatellite markers in Eucalyptus grandis and E. urophylla. Theor. Appl. Genet. 97: 816-827. https://doi. org $/ 10.1007 / \mathrm{s} 001220050961$

Brondani RPV, Williams ER, Brondani C and Grattapaglia D (2006). A microsatellite-based consensus linkage map for species of Eucalyptus and a novel set of 230 microsatellite markers for the genus. BMC Plant Biol. 6: 20. https://doi. org/10.1186/1471-2229-6-20

Byrne M, Marquez-Garcia MI, Uren T, Smith DS, et al. (1996). Conservation and genetic diversity of microsatellite loci in the genus Eucalyptus. Aust. J. Bot. 44: 331-341. https://doi.org/10.1071/BT9960331

Carvalho AO, Alfenas AC, Maffia LA and Carmo MGF (1998). Resistência de espécies, progênies e procedências de Eucalyptus à ferrugem, causada por Puccinia psidii Winter. Pesqui. Agropecu. Bras. 33: 139-147.

Danner MA, Ribeiro JZ, Zanette F, Bittencourt JVM, et al. (2013). Mendelian segregation in eight microsatellite loci from hand-and-open-pollinated progenies of Araucaria angustifolia (Bert.) O. Kuntze (Araucariaceae). Silvae Genet. 62: 18-25.

Doyle JJ and Doyle JL (1987). A rapid DNA isolation procedure for small quantities of fresh leaf tissue. Phytochemistry 19: 11-15.

Faria DA, Mamani EMC, Pappas Jr GJ, and Grattapaglia D (2011). Genotyping systems for Eucalyptus based on tetra-, penta-, and hexanucleotide repeat EST microsatellites and their use for individual fingerprinting and assignment tests. Tree Genet. Genomes 7: 63-77. https://doi.org/10.1007/s11295-010-0315-9

Gillet E and Hattemer HH (1989). Genetic analysis of isoenzyme phenotypes using single tree progenies. Heredity 63: 135-141. https://doi.org/10.1038/hdy.1989.84

Goudet J (2002). FSTAT (Version 2.9.3.2.): a computer program to calculate F-statistics. Heredity 86: 485-486. https://doi. org/10.1093/oxfordjournals.jhered.a111627

Grattapaglia D, Vaillancourt RE, Shepherd M, Thumma BR, et al. (2012). Progress in Myrtaceae genetics and genomics: Eucalyptus as the pivotal genus. Tree Genet. Genomes 8: 463-508. https://doi.org/10.1007/s11295-012-0491-x

Harfouche A, Meilan R and Altman A (2014). Molecular and physiological responses to abiotic stress in forest trees and their relevance to tree improvement. Tree Physiol. 34: 1181-1198. https://doi.org/10.1093/treephys/tpu012

Hodge GR and Dvorak WS (2015). Provenance variation and within- provenance genetic parameters in Eucalyptus urophylla across 125 test sites in Brazil, Colombia, Mexico, South Africa and Venezuela. Tree Genet. Genomes 11: 11-57. https://doi.org/10.1007/s11295-015-0889-3

Genetics and Molecular Research 16 (3): gmr16039713 
Kumar S, Echt C, Wilcox PL and Richardson TE (2004). Testing for linkage disequilibrium in the New Zealand radiata pine breeding population. Theor. Appl. Genet. 108: 292-298. https://doi.org/10.1007/s00122-003-1352-7

Manoel RO, Freitas MLM, Tambarussi EV, Cambuim J, et al. (2015). Mendelian inheritance, genetic linkage, and genotypic disequilibrium at microsatellite loci in Genipa americana L. (Rubiaceae). Genet. Mol. Res. 14: 8161-8169. https://doi.org/10.4238/2015.July.27.4

Matschiner M and Salzburger W (2009). TANDEM: integrating automated allele binning into genetics and genomics workflows. Bioinformatics 25: 1982-1983. https://doi.org/10.1093/bioinformatics/btp303

Moraes MA, Kubota TYK, Silva ECB, Silva AM, et al. (2015). Mendelian inheritance, linkage, and genotypic disequilibrium in microsatellite loci of Hymenaea stigonocarpa Mart. exHayne (Fabaceae-Caesalpinioideae). Genet. Mol. Res. 15: 1-8.

Randall BW, Walton DA, Lee DJ and Wallace HM (2015). Comparison of three pollination methods for Eucalyptus argophloia, a small-flowered eucalypt. Ann. For. Sci. 72: 127-133. https://doi.org/10.1007/s13595-014-0407-z

Sokal RR and Rohlf FJ (1981). Biometry: The Principles and Practice of Statistics in Biological Research. Copyright Ltd., New York.

Tambarussi EV, Vencovsky R, Freitas MLM and Sebbenn AM (2013). Mendelian inheritance, genetic linkage, and genotypic disequilibrium at nine microsatellite loci of Cariniana legalis (Mart.) O. Kuntze. Genet. Mol. Res. 12: 5442-5457. https://doi.org/10.4238/2013.November.11.6

Tarazi R, Sebbenn AM, Mollinari M and Vencovsky R (2010). Mendelian inheritance, linkage and linkage disequilibrium on microsatellite loci of Copaifera langsdorffii Desf. Conserv. Genet. Resour. 2: 201-204. https://doi.org/10.1007/ $\underline{\text { s12686-010-9230-5 }}$

Genetics and Molecular Research 16 (3): gmr16039713 